Fecha de recepción: diciembre 2012 Fecha de aceptación: septiembre 2013 Versión final: septiembre 2014

\section{Abstracción y expresión. Una reflexión de base filosófica sobre los procesos de diseño}

Sandra Navarrete ${ }^{*}$

Resumen: En diseño no se debate de dónde proviene el sustento conceptual de la actividad creativa. Existe la creencia de que el proceso proyectual toma como base al conocimiento teórico si su postura es racional, y lo niega si es intuitivo. Se afirma que la teoría limita la creatividad.

Para poder comprender el origen de esta postura, es necesario acercarnos a la disciplina que estudia el pensamiento humano: la filosofía. En diferentes corrientes filosóficas, desde los orígenes de la cultura occidental, se ha hablado de la razón y de la intuición, de lo abstracto y de lo expresivo. Platón marca el inicio de la tendencia abstracta, con su concepción de la IDEA. Aristóteles es el filósofo que a la idea le incorpora la SUSTANCIA, que se percibe con los sentidos. De esta forma, desde la antigüedad clásica, quedaron definidas las dos líneas básicas del pensamiento, que explican la diferencia fundamental de las dos posturas del diseño: la abstracta y la expresiva.

Sin dudas, la división tiene su explicación en el pensamiento filosófico, pero ¿por qué los diseñadores se inclinan por una de estas dos posturas? Es indispensable indagar en las bases psicológicas que predisponen a las personas a actuar de modo racional o intuitivo. La teoría de Jung, es de enorme importancia en esta propuesta reflexiva al abrir nuevas perspectivas. A la dualidad razón-intuición Jung incorporó dos nuevas variables, también presentes en el diseño: la sensación y el sentimiento.

Con este básico acercamiento a la filosofía y a la psicología se puede comprender una compleja realidad del diseño: se presenta una postura racional, que toma al conocimiento teórico como fuente de inspiración y otras propuestas se inclinan por lo sensorial, y por lo tanto la niegan, considerándose "intuitivas". Esta división es una constante que se evidencia en los procesos de enseñanza-aprendizaje y en la práctica profesional. De allí, la gran dificultad que se presenta en la construcción de las bases epistemológicas del diseño. Es de gran importancia reconocer que el conocimiento teórico es soporte de las dos tendencias de diseño (la abstracta y la expresiva), para poder llevar el diseño al campo de las disciplinas capaces de definir su propia base teórico-científica.

Palabras clave: abstracción - expresión - intuitivo - proyectual - enseñanza-aprendizaje.

[Resúmenes en inglés y portugués en las páginas 36-37]

${ }^{(*)}$ Investigadora del Departamento de Investigaciones Científicas, Tecnológicas y Vinculación y Profesora Titular en la Universidad de Mendoza. Miembro del Comité Doctorado, Universidad de Palermo. Miembro del Comité Doctorado y Profesora Titular, en la Universidad Nacional de San Juan. Profesora Titular en la Universidad San Martín de Porres, Lima y en la Universidad Nacional de Cuyo. 
El camino lleva por dos campos (que hoy implican sendos peligros): a la derecha se halla el empleo abstracto y emancipado del color en forma geométrica (ornamentación), a la izquierda la utilización más real, y prácticamente paralizada por las formas externas, del color en forma corpórea (fantasía). Al mismo tiempo existe (quizá sólo en nuestra época) la posibilidad de avanzar hacia ambos limites y llegar a traspasarlos. Tras ellos (aquí abandono mi camino de esquematización) y a la derecha se halla la pura abstracción (es decir, la abstracción que supera la de la forma geométrica); y a la izquierda, el puro realismo (es decir, la fantasía superior, fantasía en materia dura).

Entre estos extremos: libertad sin límites, profundidad, amplitud, riqueza de posibilidades y, más allá, los campos de la abstracción pura y los del realismo. (Kandinsky, 1979, p. 60)

\section{Sustento conceptual de diseño}

En algún momento del proceso proyectual intervienen los conocimientos que posee el diseñador. Estos han sido incorporados a través de la educación formal, y también por otros caminos que tienen que ver con el contexto cultural en el que habita. Existe un mundo científico que produce los avances intelectuales que mueven a la humanidad, pero también existen tradiciones que se transmiten de generación en generación y que también influyen enormemente en el ser humano. Es lo que se define como cultura ${ }^{1}$, en la que se conciben todas las teorías e ideas que intervienen en el proceso de diseño.

Es muy difundida la postura que sostiene que la genialidad en el proceso de diseño es algo innato, que sólo hay que incentivar a través de algún misterioso disparador de la creatividad. Es cierto que en la historia del arte han existido genios pero también es cierto que estos genios han estado insertos en una cultura determinada y que de alguna forma han manifestado en sus obras los rasgos predominantes de su momento histórico. Por lo tanto sus obras han tenido relación con esa cultura, con sus tradiciones y también con las teorizaciones propias de su época. Es una genialidad profundamente vinculada con el conocimiento, las ideas han emanado de un determinado contexto temporal.

La creencia de que es posible separar la teoría de la práctica proyectual se ha evidenciado en gran parte de las escuelas de diseño actuales (indudablemente influenciadas por la Bauhaus), situación que también notamos en docentes y alumnos de nuestros ámbitos académicos latinoamericanos. Esta división entre teoría y práctica proyectual tiene su origen a mediados del siglo XIX, con la industrialización que creó una confianza ilimitada en el progreso, con una ingenua mirada hacia el futuro. El diseño moderno ha basado sus premisas en esta búsqueda de la vanguardia que llevó al alejamiento de la reflexión que toma conceptos del pasado.

Así, en los ámbitos académicos y profesionales se ha generado una duda que ha afectado sensiblemente los procesos proyectuales de los últimos tiempos: ¿Tiene sentido conocer la teoría del diseño? La insistencia del período entre guerras de negar las teorías academicis- 
tas, ha dado forma a la idea de que no es necesario el sustento teórico. En tiempos más recientes, incluso hasta nuestros días con la hipermodernidad, se insiste en esta postura light (Rojas, 1995), que se acerca peligrosamente a la negación del componente cultural del diseño.

Actualmente se observan con claridad dos actitudes muy definidas frente al modo de diseñar: por un lado están los diseñadores que utilizan su formación teórico-crítica como fuente de inspiración, y por otro lado están los que creen que la genialidad es algo innato, consideran que el conocimiento entorpece el proceso creativo, buscan en diferentes estímulos, de origen misterioso, la fuente de las ideas geniales.

Es un hecho que todos ejercitamos una reflexión proyectual. Lo que varía son las fuentes que sustentan esa reflexión (bibliográficas, o de la observación que permite inferir conceptos) y en qué medida se las utiliza. Pocos se detienen a analizar esta realidad, cuánto se teoriza, cuánto se percibe, cómo se combinan estos estímulos, en definitiva: cuál es el aporte de la reflexión al proceso proyectual. Toma mayor relevancia el problema cuando esta indefinición se traslada a las aulas, al ámbito académico. De allí que se hace indispensable debatir sobre el proceso de intercambio teórico-práctico, para poder comprender el rol que tiene la formación teórica en el diseño.

\section{Lo racional y lo intuitivo}

El espacio y el tiempo son entre sí como la materia y la memoria, como el cuerpo y el alma, responden a dos modos mentales del hombre, que son radicalmente distintos, y aún opuestos en cierto sentido: el pensamiento y la intuición (Bergson, en Marias, 1996).

Cuando hablamos del aporte reflexivo que realiza la teoría al proceso de diseño, tendemos a pensar que este aporte se da solamente a través del camino racional ya que se asocia reflexión con razón. Herbart considera la razón como "facultad de la reflexión". Para Baldwin es el "principio constitutivo, regulador del espíritu", para Schopenhauer es una función con la que se elaboran conceptos (conclusiones, principios generales). Para Kant la razón es la fuente de la idea. Para Jung es una cierta disposición que hace posible el pensar, el sentir y el obrar acordes con determinados valores objetivos.

Sin embargo, si estudiamos el verdadero significado de la reflexión vemos que en ella hay componentes racionales y también intuitivos. Son dos caminos paralelos (no opuestos) para llegar al conocimiento.

Se ha ido afirmando la idea de que existe un modo de proyectar intuitivo, proveniente de una imaginación de origen misterioso, y otro modo de proyectar racional, metodológico, sin creatividad. "La idea de que el pensamiento creador es opuesto al razonamiento es tan equivocada como difundida" (Bunge, 1996, p. 142).

El pensamiento racional procede de la lógica y de la observación. El pensamiento intuitivo es una forma de conocimiento independiente de la experiencia o la razón, pero no opuesto. En algunos casos “intuición” designa una facultad prerracional (intuición sensible); en 
otros, una aptitud suprarracional (intuición pura, intuición de esencias, intuición mística); en otros, por fin, una variación de la razón (intuición intelectual). La intuición tiene que ver con modos de 'percepción' (identificación rápida, capacidad de interpretación), de 'imaginación' (capacidad de representación), de 'inferencia', de 'síntesis' (visión global), de 'comprensión' (sentido común) y de 'evaluación'. En cualquier trabajo científico, desde el planteo del problema, la construcción de las hipótesis, interviene la percepción de hechos o signos, la imaginación, la formación de conceptos de diverso grado de abstracción y la generalización inductiva; la deducción, tanto formal como informal; y muchas otras maneras de formar, combinar y rechazar ideas. Del mismo modo ocurre en el proceso proyectual. Pero se tiende a enfatizar los primeros aspectos perceptivos e imaginativos, en desmedro de aquellos en que colabora con el pensamiento racional y científico (inferencia, comprensión, evaluación).

La intuición es el punto inicial de la imaginación. Sin embargo, la creatividad tan alabada por los intuicionistas y los gestaltistas no proviene de la nada. En la ciencia y en la tecnología, la novedad surge de la observación, la comparación, el ensayo, la crítica y la deducción; no hay conocimiento nuevo que no esté determinado de alguna manera por conocimientos anteriores y relacionando lógicamente con éstos.

\section{Una mirada filosófica de la realidad}

Hoy sabemos que en todo proceso de diseño se realiza algún tipo de reflexión. Pero también la realidad nos muestra que pocos se detienen a analizar de dónde proviene el sustento conceptual, el problema se simplifica en que se diseña en forma racional o intuitiva. Para poder comprender el origen de esta creencia, se hace indispensable acercarnos a la disciplina que estudia el pensamiento humano: la filosofía.

¡Platón y Aristóteles! He aquí no sólo dos sistemas, sino dos naturalezas humanas distintas, que desde tiempos indeciblemente lejanos y bajo todos los hábitos imaginables se enfrentan mas o menos hostilmente. (...) Siempre se trata de Platón y de Aristóteles, aunque sean otros los nombres que se mencionan. Naturalezas febriles, místicas, platónicas, desentrañan con reveladora virtud, las ideas, y los símbolos inherentes a ellas, de los abismos de su espíritu. Naturalezas prácticas, ordenadoras, aristotélicas, construyen con estas ideas y estos símbolos un sistema firme, una dogmática y un culto. (Heine en Jung, 1972, p. 11).

En las dos líneas originales de la filosofía occidental está la base de las dos posturas del diseño: la abstracción y la expresión. La disposición a lo expresivo se vincula con lo sensorial, empírico. La opuesta, abstracta, es resultado de un proceso racional.

Hay dos tendencias en el diseño porque hay dos formas de entenderlo, como la IDEA generadora que se ha concretado, o como una composición que toma características propias 
a través de su MATERIA. Estos principios tienen su origen filosófico. Platón es el padre de la IDEA, separó el pensamiento, de lo que es percibido por los sentidos. Los objetos ideales son esencias universales que sólo puede conocer la mente. Aristóteles no coincidió con Platón en su separación del objeto y la idea, puso énfasis en la importancia de la MATERIA. Dio lugar a los sentidos (particularmente al tacto) y concibió la 'Estética' (del griego aesthetikos: perteneciente a la percepción sensorial). De estos conceptos derivan distintas líneas filosóficas, presentes en la concepción del diseño.

Platón sostiene que el sujeto nace con conocimientos (son innatos), que necesita estímulos de la realidad para 'despertarlos', el sujeto es el soporte fundamental de los conocimientos. Con su Doctrina de las Ideas, formuló una serie de conceptos fundamentales para el desarrollo del arte occidental. Es la base del término habitualmente utilizado de idea generadora, que son patrones o modelos sobre los que se construyen y entienden las cosas, y hacia cuya perfección aspiran constantemente. Platón presentó el EIDOS como ideas absolutas y sostuvo que el hombre debía considerarlas como el ideal de perfección. La 'esencia' es lo que hace posible que una cosa sea, y el absoluto es el 'concepto', la fuente de todo saber que es independiente y por tanto libre. En el arte lo absoluto es una manifestación 'sensible', y por tanto 'intuida'. El último estadio del espíritu absoluto es la filosofía, donde la idea ya no es intuida sino concebida y elevada a concepto.

Aristóteles, rechazó los arquetipos de Platón y prefirió el mundo tangible conocido a través de la experiencia de los sentidos, en lugar de la abstracción ideal platónica. Para este filósofo, el hombre cuando nace es ignorante, es una 'tábula rasa' (en blanco) sobre la cual se irán grabando las impresiones sensibles, producto de sus experiencias con los objetos. El objeto es el soporte fundamental de los conocimientos.

Aristóteles, al rechazar la dialéctica platónica, dio origen a un nivel más elevado de la filosofía: la metafísica. Plantea un problema muy concreto: ¿qué es lo que hace que un ser sea lo que es? ¿qué es lo que hace que un hombre sea un hombre, que un objeto de diseño sea verdaderamente creativo? Se trata de entender la esencia de un ser.

'Esencia' es el concepto filosófico que designa aquello que hace que una cosa sea lo que es. El estudio de la esencia ha sido una constante en la historia de la filosofía. Platón inició este análisis afirmando que la esencia de la realidad es su idea. Aristóteles diseñó el concepto de ousía para designar la esencia de una realidad.

'Accidente' se opone a sustancia. De ahí que se emplee el término 'accidental' como contrario a 'sustancial'. Lo accidental designa aquello que pertenece a una cosa, pero no de un modo necesario y constante. De hecho, si un accidente desaparece no queda afectada la identidad o modo de ser de aquello a lo que pertenece. Las tendencias del diseño contemporáneo nos permiten identificar estilos, pero no hacen a la esencia de ese estilo, es sólo su aspecto más superficial, 'accidental'.

En este acercamiento filosófico, es insostenible la dualidad razón-intuición. Los pares divergentes son la razón y la experiencia sensible. Platón marca el inicio de la tendencia abstracta, con su concepción de la IDEA. Aristóteles es el filósofo que a la idea le incorpora la SUSTANCIA, lo material, lo que se percibe con los sentidos. De esta forma quedan diferenciadas las dos líneas básicas del pensamiento, que explican la diferencia fundamental de las dos grandes tendencias de diseño: 'la abstracta y la expresiva'. 


\section{Abstracción y expresión en diseño}

A partir de la filosofía quedaron diferenciadas dos líneas básicas del pensamiento (idealismo y emprirismo), que explican la diferencia fundamental de las dos posturas que asumen los diseñadores frente a la reflexión teórica. Pero además se comprende el origen de las tendencias abstractas y expresivas del diseño.

Se hace necesario aclarar los términos utilizados habitualmente:

ABSTRACCIÓN. Abstraer significa literalmente "poner aparte", "arrancar”... Cuando el poner aparte es mental y no físico la abstracción es un modo de pensar mediante el cual separamos conceptualmente algo de algo. Así, por ejemplo, las figuras de que trata la geometría pueden considerarse como abstracciones de figuras concretas en las cuales solamente se tienen en cuenta ciertas propiedades. Al abstraerse se separa lo que se estima general, universal, necesario o esencial de lo individual, casual y contingente (Ferrater Mora, 1979, p. 38).

EXPRESIONISMO, corriente artística que buscaba la expresión de los sentimientos y las emociones del autor, más que la representación de la realidad objetiva. El artista expresionista trató de representar la experiencia emocional en su forma más completa, sin preocuparse de la realidad externa sino de su naturaleza interna y de las emociones que despierta en el observador.

\section{Predisposiciones psicológicas del diseñador}

Era claro que la división tenía su explicación en el pensamiento filosófico, pero ¿por qué los diseñadores se inclinan por una de estas tradiciones? Se hizo indispensable indagar en las bases psicológicas que predisponen hacia la abstracción o hacia lo empírico - expresivo. Con el aporte de los estudios psicológicos de Jung, a la dualidad razón (abstracción) - intuición (expresión) se incorporaron dos nuevas variables, también presentes en el diseño: la sensación y el sentimiento.

Observando estudios psicológicos vemos que hay diferentes modos de actuar que provienen del comportamiento mental. Por un lado está la 'mente racional', consciente, capaz de analizar y meditar. Este modo de pensamiento está apoyado en la lógica y en la observación. El pensamiento conceptual o inteligencia es el método de conocimiento científico que tiende a la especialización. Por otro lado, la 'mente emocional' es otro tipo de conocimiento, impulsivo, a veces ilógico. Cuanto más dominante se vuelve la mente emocional, se torna más ineficaz la racional. Estas dos mentes operan de modo armónico, entrelazando sus diferentes formas de conocimientos, para guiar la conducta. Existe un equilibrio 
en el cual la emoción alimenta la mente racional y el intelecto depura la energía ingresada por los sentimientos. Es indispensable la coordinación exacta entre ambas, ya que cuando aparecen las pasiones, la mente emocional aplasta a la racional.

El punto inicial es la crítica a la psicología tradicional que estudia la inteligencia a través de coeficientes matemáticos (C.I) que solo miden el comportamiento racional, descuidando un aspecto fundamental: 'la emoción'. Las emociones son impulsos para actuar. La raíz latina es motore que proviene del verbo mover, al que se le agrega el prefijo "e" (alejarse). Es decir que la significación profunda del término implica movimiento, una tendencia a la acción. Hay una variedad muy amplia de emociones (y de matices), entre las que pueden mencionar la ira, el miedo, la felicidad, el amor, la sorpresa, el disgusto, la tristeza. Estas tendencias biológicas están moldeadas por las experiencias adquiridas de la vida, y por la cultura.

La mente emocional es más rápida que la mente racional y se pone en acción sin detenerse a analizar la situación (característica de la razón). Se dispara generalmente ante situaciones que requieren una respuesta inmediata, por ejemplo, ante el peligro. Este rápido modo de percepción sacrifica la exactitud a favor de la velocidad y la primera reacción depende del cuadro general. Asimila la situación global, sin realizar un estudio reflexivo de sus componentes. Y de este modo se incorpora a la memoria. El problema es que éstas impresiones intuitivas que ingresan en la mente sin el tamiz racional, pueden ser falsas o erróneas A la mente racional le lleva más tiempo que a la emocional registrar y responder. Y en la emoción hay vías rápidas (la percepción inmediata) y vías más lentas (a través de la reflexión). En estas últimas hay una mutua colaboración, ya que la mente racional, que recibe el aporte de la percepción, enriquece a la mente emocional controlando las reacciones. La mente emocional es asociativa, toma elementos que simbolizan una realidad conocida (o dispara un recuerdo de la misma) para encontrar similitudes con la realidad nueva. Por eso son tan importantes los símbolos, las metáforas, las imágenes, al igual que el arte. Este proceso de asociación de imágenes con las contenidas en la memoria, es comparable al 'proceso primario' de pensamiento desarrollado por Freud. Es la lógica de los sueños, de los mitos, de la poesía, y del pensamiento infantil.

En este proceso asociativo, en que una cosa significa otra, lo que importa no es su verdadera identidad sino cómo es percibida. Esto implica ciertos riesgos, semejantes al pensamiento infantil. Entre sus características está ser categórico: todo es blanco o negro, sin matices. Es personalizado, todo gira en torno a quien percibe, es subjetivo. Es autoconfirmador, se aferra a las convicciones y recuerdos que confirman su creencia, descartando cualquier evidencia objetiva.

Con este enfoque, nos ha llegado desde la Antigüedad una diferenciación de tipos humanos, basada estrictamente en lo biológico. Así, la filosofía gnóstica establece las tres funciones psicológicas fundamentales: pensar - sentir - percibir, donde:

- en el pensar predomina lo abstracto

- en el sentir y percibir, lo matérico 
En el siglo XIX, Nieztche aborda esta dualidad, cuando habla de lo dionisíaco y lo apolíneo. Jordan dice:

Hay dos caracteres fundamentalmente distintos (...) uno en el que es fuerte la tendencia a la actividad y débil la tendencia a la reflexión y otro en el que la tendencia a la reflexión predomina, mientras el impulso activo es más débil. Entre estos dos extremos hay innumerables matices (Jung, 1972, p. 200).

Desde el punto de vista pragmático de James, el racionalismo empieza con lo total y universal, unifica las cosas. El empirismo, en cambio, empieza en la parte y hace del todo una 'colección', es pluralista. James realiza un pormenorizado análisis de las características de ambos, y destaca los prejuicios que cada uno tiene sobre el otro. El enfrentamiento llevado a su extremo, da un resultado peligroso. Por un lado, la preponderancia empírica supone la opresión del pensamiento, y la perdida teórica en una disciplina. Por otro lado, la ausencia de la práctica experimental lleva a que la teoría se transforme en mito.

Jung aclara que el término racional es aplicable a ambas posturas: hay un racionalismo lógico y un racionalismo de los sentimientos. La psicología analítica de Carl G. Jung se basa en la comprensión de la estructura y la dinámica de la psique (entendida como la totalidad del ser: lo consciente y lo inconsciente).

Para describir cómo trabaja la energía psíquica, Jung desarrolló los 'tipos psicológicos'. Postuló las cuatro funciones psíquicas, que trabajan en opuestos (una función superior, más diferenciada, compensada por la opuesta inconsciente).

La sensación nos dice que algo existe.

El pensamiento nos dice qué es lo que existe.

El sentimiento nos dice si es bueno o malo.

La intuición nos dice de dónde viene o a dónde va.

Esta es la propuesta que realizó Jung en su tesis doctoral, en la que hace un análisis de la tesis de Worringer que, al hablar de las dos posturas que asume el hombre en su concepción del arte, está demostrando la existencia de las disposiciones psíquicas.

En 1908, W. Worringer publica Abstraktion und Einfühlung(Worringer, 1953), obra que conoció una amplia difusión y que fue utilizada por los artistas (especialmente por el círculo de Kandinsky) como confirmación teórica de sus desarrollos formales.

La estética del Einfühlung (término que puede traducirse como "introducción del sentimiento", "sentir total", "simpatía simbólica", consenso, empatía) nace del compromiso entre el pensamiento idealista y la investigación psicológica para responder a la pregunta de por qué los hombres son atraídos o repelidos por las formas de los fenómenos, tanto del arte como de la naturaleza (De fusco, 1968, p. 107). 
El afán de abstracción se revela como un intento de superación del relativismo, de la angustia, del caos, por una enajenación del yo, por un desprenderse de la individualidad en la intuición de una armonía que muestra la belleza invisible de la esencia (Worringer, 1953, pp. 34-39).

Worringer, establece una relación directa entre "angustia" y "abstracción". La abstracción es una afirmación que ha excluido completamente la negación, que afirma tanto lo positivo como lo negativo, lo visible como lo invisible, lo individual como lo universal, lo bueno como lo malo, lo destructivo como lo constructivo (Klee,1959, p. 76).

La tendencia a la geometría elemental fue tratada por Worringer, quien explica que "la abstracción es una experiencia histórica recurrente". Las líneas, los planos, los volúmenes, los colores, se asocian, se aceptan o rechazan gracias a sensaciones análogas preexistentes en uno (el equilibrio, la calma, etc). Según este autor existe en el hombre primitivo una tendencia a reducir lo desconocido a figuras abstractas. Por otro lado, en culturas más evolucionadas como la clásica, hay otra organicidad en el manejo de las formas.

Su definición de con-sentimiento se apoya en Lipps, que afirma que al percibir un objeto se experimenta un impulso que proviene del comportamiento íntimo del objeto, de alguna manera se comunica con nosotros.

"El con-sentimiento es, pues, una especie de proceso de percepción que se caracteriza por el hecho de que, por la vía del sentimiento, un contenido esencial psíquico es situado en el objeto que es así sometido a introyección” (Jung, 1972, p. 385).

El objeto parece animado, dotado de expresión propia. Pero en realidad el observador 'proyecta' contenidos inconscientes, por lo que en psicología analítica al con-sentimiento se le llama 'transferencia' (término utilizado por Freud). Lipps afirma que "sólo cuando este con-sentimiento existe son las formas bellas".

Ahora, si la forma no tiene vida (es inorgánica) se la llama abstracta, y no se puede consentir con ella. Un ser vivo sólo puede con-sentir con otro ser vivo (la naturaleza). La tendencia a la creación artística abstracta es entonces contraria a la vida y según Worringer proviene de un estado de angustia espiritual. El objeto orgánico entonces asume una actitud de asimilación (se vacía de sus propios contenidos y adopta el significado de quien lo observa). En cambio, en la disposición abstracta, el objeto se resiste a ser interpretado, tiene su propia vida independiente de quien se relaciona con él. En los pueblos primitivos los signos geométricos tienen más valor mágico que de belleza. Según Worringer, contrastaban el miedo que le causaban los fenómenos naturales con aquello que era símbolo de reposo, de calma: lo abstracto.

"Estas formas abstractas y legítimas son, pues, las formas únicas y supremas en las que el hombre puede reposar frente a la confusión enorme de la visión del mundo" (Worringer, 1953, p. 21).

En las culturas orientales hay mayor disposición a lo abstracto, ya que le atribuyen un significado mágico, una vida propia a los objetos frente al temor que producen los fenómenos naturales; el mundo es amenazante, por eso hay que abstraerse de él. 
De esta manera, este crítico de arte muestra su inclinación hacia la disposición sensible, cuya manifestación está en la corriente expresiva. Esta es la razón por la que gran parte de los estilos contemporáneos se identificaron con esta teoría, (principalmente el Art en la primera mitad del siglo XX).

\section{Objetividad y subjetividad en el proceso de enseñanza-aprendizaje}

Ningún profesional va a afirmar que proyecta sin conocimiento. Considera que la práctica le ha dado suficiente experiencia, y que lo que ha aprendido empíricamente es válido como conocimiento, porque es lo que él conoce. De este modo, se aferra a esa experiencia y debate apasionadamente con los profesionales que buscan por otros caminos, un conocimiento menos subjetivo. Así se crea una inevitable tensión entre los que aprendieron en la calle, y los que se forman por caminos académicos más sistematizados (posgrados, lectura crítica, etc.). ¿Quien tiene la verdad?

Para responder esta pregunta (que tal vez no tenga respuesta) es necesario aclarar qué se considera 'conocimiento'. Para la psicología, la cognición engloba los procesos de atención, percepción, memoria, razonamiento, imaginación, toma de decisiones, pensamiento y lenguaje. Sócrates enseñó que cada persona tiene pleno conocimiento de la verdad última dentro de su alma y que sólo necesita llevarlo a la 'reflexión' consciente para darse cuenta. Según Collingwood, la cultura griega elaboró una distinción entre dos formas de pensar:

Opinión (doxa): es un semi-conocimiento empírico que se tiene de cuestiones que están en permanente cambio. Tiene relación directa con la experiencia personal, individual, subjetiva. Puede transmitirse como valiosos aportes de la visión de maestros, que ayudan a tomar conciencia directa de la realidad concreta. Pero cómo transmitir lo que se ha vivido? Como poner al discípulo en las mismas condiciones para que pueda comprender la experiencia ajena? La experiencia es muy valiosa, siempre que estimule el acercamiento al conocimiento universal, que contemple diferentes posturas de diseño, más allá de la 'opinión' o gusto personal del maestro.

Conocimiento (noûs): tiene validez universal, está fundado en la razón crítica, está construido a partir de la reflexión teórica. Dado que se ha pasado de la instancia personal a la aceptada por científicos u otros profesionales idóneos, que se han elaborado conceptos a partir de la formación intelectual y práctica, estos conceptos pueden transferirse sin necesidad de poner al aprendiz en situación de experimentación personal. La crítica que guía al estudiante tiene sustento, que en el mejor de los casos tiene el complemento de la práctica, y de este modo la formación es completa.

En la acción proyectual, es muy peligrosa la opinión personal. Dado su carácter subjetivo, no se puede transmitir, se cae en recetas que no llevan a la formación de nuevos proyectistas. Se diseña a modo del tutor, y si éste cometió errores, los mismos serán repetidos 
por sus sucesores, sin un filtro crítico. Se estimula la misteriosa creatividad a través del procedimiento de diseño de prueba y error. Es impensable que este camino llegue a buen destino, si se compara con otras disciplinas, de igual compromiso con la sociedad, como la medicina.

Tampoco es adecuado pensar que un conocimiento teórico sólido va a proporcionar soluciones proyectuales adecuadas. Se cae en metodologismos dogmáticos, que nada tienen que ver con la realidad socio-cultural. Quienes tienen una formación conceptual profunda, también son conscientes de la necesidad de poner a prueba los conocimientos en la práctica proyectual y de materialización.

\section{Conocimiento teórico y ciencia en diseño}

La resistencia a teorizar de manera consistente en los talleres proyectuales, a poder argumentar con solidez las propuestas de diseño, a encontrar en la realidad cultural y social los verdaderos estímulos creativos, están presentes con mayor énfasis en los docentes que en los alumnos.

Ciencia (en latín scientia, de scire, 'conocer'), término que se emplea para referirse al conocimiento sistematizado en cualquier campo, pero que suele aplicarse sobre todo a la organización de la experiencia sensorial objetivamente verificable. La búsqueda de conocimiento en ese contexto se conoce como 'ciencia pura', para distinguirla de la 'ciencia aplicada' -la búsqueda de usos prácticos del conocimiento científico- y de la tecnología, a través de la cual se llevan a cabo las aplicaciones.

Tanto el diseño como otras disciplinas creativas han permanecido en la investigación aplicada, no han logrado sistematizar los conocimientos para llegar al campo de las ciencias puras. Sin embargo tiene todo el potencial para lograrlo.

\section{Hacia una epistemología del diseño}

El punto de partida del debate está en la relación TEORÍA-PRAXIS. Se sabe que se realiza algún tipo de reflexión cuando se proyecta. En los ámbitos universitarios no se toma conciencia de la complejidad de este proceso, se tiende a simplificar, la práctica proyectual se presenta como un mecanismo misterioso. No se tiene en cuenta que todo proyectista reflexiona, que lo que cambia es el referente que cada uno utiliza. La formación crítica no sólo se adquiere en bibliografía reconocida, otros medios gráficos como las revistas ofrecen elementos para la reflexión. El problema entonces es hacer consciente este proceso para quienes consideran innecesario el conocimiento teórico. En los talleres no se debate de dónde proviene el sustento conceptual, se afirma que se diseña en forma racional o intuitiva, y esta última es exaltada por ser más creativa. 
Es también una creencia entre los diseñadores, que se puede aprender solamente de lo que se ve (sin una reflexión crítica más profunda). Las sensaciones, sin ninguna duda, suponen algún tipo de conocimiento, pero el hombre tiene otros modos superiores de saber, expuestos en la filosofía clásica:

- En primer lugar la EXPERIENCIA que es el conocimiento de las cosas de un modo individual, inmediato, y concreto. La experiencia no se puede transferir, se puede poner a otro en condiciones de adquirir esa misma experiencia. Esto es algo que ocurre en la enseñanza en los talleres, o en los estudios profesionales.

- Otro modo de saber más elevado es el ARTE o TÉCNICA. La tékhne es un saber hacer, dar respuesta individual a un problema concreto. Este tipo de conocimiento pone en juego las capacidades individuales y su formación, implica un mayor grado de reflexión.

- La tékhne nos da el qué y el porqué de las cosas, pero no sus causas o principios primeros. A ellos llegamos con la SABIDURÍA, o sophía, que implica demostrar las cosas desde sus principios. La ciencia, o saber demostrativo se llama en griego epistéme (esta es la ciencia que busca Aristóteles). Pero los principios no son demostrables (por eso son principios), hace falta una intuición de ellos, esta es la noûs, que junto con la epistéme, compone la verdadera SABIDURÍA. Aquí aparece el origen del conflicto razón-intuición. Suele pensarse que la intuición es un camino diferente del intelectual, más adelante demostraremos que la intuición es parte del pensamiento racional y por lo tanto está condicionada por el conocimiento o sabiduría.

Esta clasificación de las formas de adquirir el conocimiento, nos remite a Aristóteles, que nos permite dar mayor claridad al valor de la teoría frente a la práctica (aspecto fundamental en esta argumentación):

- Poíesis: de donde viene poesía, del griego producción, fabricación (construir un objeto).

- Prâxis: o práctica, es una acción, una actividad que tiene como fin ella misma (hacer política). Es suficiente en sí misma ya que no necesita un objeto externo. Por ello es superior a la poiesis.

- Theoría: o contemplación, es un modo de prâxis, no se oponen, pero la theoría es la acción suprema, ya que la prâxis, depende de algo externo (la política necesita de una ciudad y sus habitantes). Por esto la theoría, que sólo necesita de la mente del hombre teórico, es superior a la prâxis, desde la perspectiva aristotélica.

El diseño es una disciplina que comparte las tres categorías enunciadas por Aristóteles. Es acción, aunque no es suficiente en sí misma, por ello se podría decir que está más cerca de la poética que de la praxis (siempre hay un objeto como principio de acción). Lo que es innegable es que está absolutamente relacionada con las ciencias teóricas. Desde el punto de vista aristotélico la teoría y la praxis no se oponen, se complementan. 
Hasta aquí la interpretación es válida para el diseño: se entiende que la teoría es la reflexión y la praxis es la actividad proyectual. El problema se plantea cuando empezamos a analizar el significado de la reflexión, cuánto contiene de racional, cuánto de observación o percepción, cuánto de intuición. Todos estos aspectos parecen caminos divergentes. Tal es así que entre los diseñadores han surgido designaciones que tiene que ver con estas variantes: diseñadores racionales, intuitivos (término que implica mayor creatividad), etc. El actual desafío entonces, es concientizar a los profesores, que esas mentes abiertas de nuestros estudiantes, están listas para enfrentar el complejo mundo que se nos presenta, donde la apabulladora "información" está postergando la verdadera "formación", que llevará al diseño al campo científico.

\section{Notas}

1. En esta reflexión se utiliza el término cultura como conjunto de rasgos distintivos de una sociedad en un período determinado, tales como modos de vida, arte, invenciones, tecnología, sistemas de valores, tradiciones y creencias. A través de la cultura se expresa el hombre, toma conciencia de sí mismo, cuestiona sus realizaciones, busca nuevos significados y crea obras que le trascienden

\section{Bibliografía}

Aristóteles. (1967). Obras completas. Buenos Aires: Bibliográfica Omeba.

De Fusco, R. (1968). L`idea di Architettura. Storia de la crítica da Viollet-le-Duc a Pérsico. Editorial Gustavo Gili: Barcelona.

Ferrater Mora, J. (1979). Diccionario de filosofía. Alianza: Madrid.

Husserl, E. (1993). IDEAS. Relativas a una fenomenología pura y una filosofía fenomenológica. Primera edición en alemán, 1913. Fondo de Cultura Económica: Madrid.

Jung, C. G. (1972). Tipos psicológicos. Buenos Aires: Editorial Sudamericana.

Kandisnky, W. (1979). Über das Geistige der Kunst. Premia: México, D. F.

Klee, P. (1959). Teoria della forma e della figurazioize, Feltrinelli Editore: Milan.

Marias, J. (1996). Historia de la filosofía. Alianza Editorial: Madrid.

Rojas, E. (1995). El hombre light. Una vida sin valores. Ed. Planeta: Buenos Aires.

Worringer, W. (1953). Einfuhlung und Abstraction. $1^{\text {a }}$ edición 1908. Fondo de Cultura Económica: México. 
Summary: The roots of creative activity is a topic not much discussed in the design professional field. It is said that the design process is based on the theoretical knowledge if it is rational and denies it if it is intuitive. It is claimed that the theory limits creativity.

To understand the origin of this position, it is necessary to approach the discipline that studies human thought: philosophy. In different philosophical schools, from the origins of Western culture, there has been talk of reason and intuition, from the abstract and expressive. Plato marks the beginning of the abstract tendency, with its conception of the IDEA. Aristotle is the philosopher who adds the substance to the idea, which is perceived by the senses. Thus, from classical antiquity, were defined the two basic lines of thought that explain the fundamental difference in the two positions of design: abstract and expressive. Without doubt, the division is explained in philosophical thought, but why designers are inclined to one of these two positions? It is essential to investigate the psychological basis that predispose people to act in a rational or intuitive way. Jung's theory, is of great importance in this thoughtful proposal to open new perspectives. Jung added to the reasonintuition duality two new drivers, also present in the design: sensation and feeling.

With this basic approach to philosophy and psychology we can understand a complex reality of design: it has a rational position, which takes theoretical knowledge as inspiration and other proposals are inclined by the senses, and therefore denied it, considered "intuitive". This division is a constant that is evident in the teaching-learning and professional practice. Hence, the great difficulty that arises in the construction of the design epistemological basis. It is very important to recognize that theoretical knowledge is supporting both design trends (the abstract and expressive), to bring the design to the field of disciplines able to define their own theoretical and scientific basis.

Keywords: abstraction - expression - intuitive knowledge - projective design - teachinglearning practice.

Resumo: em design não se debate de onde provem o sustento conceitual da atividade criativa. Existe a crença de que o processo projetual tem como base o conhecimento teórico se sua postura é racional, e o nega se é intuitivo. Afirma-se que a teoria limita a criatividade. Para compreender a origem dessa postura, é necessário acercar-nos à disciplina que estuda o pensamento humano: a filosofia. Diferentes correntes filosóficas, desde as origens da cultura ocidental, falaram da razão e da intuição, do abstrato e do expressivo. Platão marca o início da tendência abstrata, com sua concepção da idéia. Aristóteles é o filósofo que à idéia lhe incorpora a sustancia, que se percebe com os sentidos. Assim, desde a Antigüidade clássica, ficaram definidas as duas linhas básicas do pensamento, que explicam a diferença fundamental das duas posições do design: a abstrata e a expressiva.

Sem dúvida, a divisão tem sua explicação no pensamento filosófico, mas, por que os designers inclinam-se por uma destas duas posturas? É indispensável indagar nas bases psicológicas que predispõem às pessoas a atuar de modo racional ou intuitivo. A teoria de Jung é importante nesta proposta reflexiva ao abrir novas perspectivas. À dualidade razão - intuição Jung incorporou duas novas variáveis, também presentes no design: a sensação e o sentimento. 
Com esta básica aproximação à filosofia e à psicologia pode-se compreender uma complexa realidade do design: se apresenta uma postura racional, que tem ao conhecimento teórico como fonte de inspiração e outras propostas se inspiram no sensorial, e, por tanto, a negam, considerando-se "intuitivas". Esta divisão é uma constante que se evidencia nos processos de ensino-aprendizagem e na prática profissional. De ali, a grande dificuldade que se apresenta na construção das bases epistemológicas do design.

É de grande importância reconhecer que o conhecimento teórico é suporte das duas tendências de design (a abstrata e a expressiva), para poder levar ao design ao campo das disciplinas capazes de definir sua própria base teórico - científica.

Palavras chave: abstracção - ensino apredizagem - expressão - intuitivo - projetual. 